\title{
Specific learning disabilities: Challenges for meaningful access and participation at higher education institutions
}

\section{Lorna M Dreyer}

Department Educational Psychology, Stellenbosch University, Stellenbosch, South Africa

lornadreyer@sun.ac.za

https://orcid.org/0000-0002-7908-298X

(Received: 7 November 2020; accepted: 26 May 2021)

\section{Abstract}

The worldview on the rights of people with disabilities has changed in pursuit of social justice, resulting in an international increase in students with disabilities enrolling at Higher Education Institutions (HEIs). This supports the need to meet the challenge to transform and attain Education for All (EFA) as a global imperative. In this research, I focussed on the experiences of students with Specific Learning Disabilities (SLDs) at a South African university. My findings suggest that although HEIs have policies that promote inclusive education, many students with SLDs still experience exclusion from full access and participation in teaching and learning. I conclude that authentic inclusion of students with SLDs requires improved awareness of institutional support structures as well as an inclusive pedagogical stance from lecturers.

Keywords: higher education, student learning, transformation, specific learning disabilities, inclusive education, social cultural theory

\section{Introduction}

According to Prosser and Trigwell (1999) teachers' and learners' perceptions of their present teaching and learning situations are fundamental since they can evoke prior experiences and impact on the teaching and learning adopted in their situations as well as on the outcomes of activities in these situations. On the one hand, there is a strong link between learning experiences of students, contextual factors (such as policies and institutional support structures), and pedagogy applied by teachers. Loughran (2013) has contended that the construct of pedagogy has been "defined, interpreted and used in many ways in the educational literature" (p. 118). On the other hand, teaching practices are closely correlated to a teacher's own worldview or paradigm that inevitably has a direct impact on the pedagogy to which they ascribe. The concept of pedagogy is often used loosely to refer to teaching but it should rather be viewed as the complex inter-relationship between teaching and learning (Flores, 2019; Loughran, 2013). It is thus important for academics at HEIs to understand how 
their own worldview impacts on their pedagogical stance and how this, in turn, affects the students' learning.

Equally significant to teaching and learning experiences of students are contextual factors that promote inclusion. With the international move towards inclusive education, many countries have adopted relevant policies. South Africa is no exception since inclusive education has been embraced since 1994 as part of the broader democratisation process (Dreyer, 2017). Currently South African HEIs are in a period of transformation that sprouted from this wider social awakening with the dawn of a democratic political dispensation in which social justice is embedded. With various policy documents such as the Strategic Policy Framework on Disability for the Post-School Education and Training System (Department of Higher Education (DoHE), 2018), South Africa's higher education system is guided to reflect social diversity and to acknowledge the need to transform. Social inclusion forms the foundation for the creation of a democratic and socially just society in which the promotion of equality, "access and fair chances of success to all who are seeking to realise their potential through higher education, while eradicating all forms of unfair discrimination and advancing redress for past inequalities" are pursued (Department of Education (DoE), 1997, section 1.14). Given the legacy of apartheid in South Africa, it is justifiable that social inclusion is focussed primarily on increasing racial access and equality particularly at former whites-only institutions (DoE, 1997).

Against this backdrop it must be acknowledged that education systems around the globe have been characterised historically by a medical model that excluded people from mainstream educational institutions based on their (dis-)abilities and special needs (Dreyer, 2017). According to the medical perspective, what was thought of as the problem with learning and development was seen primarily to be located in the individual and therefore this needed to be diagnosed to enable categorisation in order to prescribe treatment and placement into a special education setting (Department of Basic Education (DoBE), 2014). However, since the Universal Declaration of Human Rights (United Nations (UN), 1948), the momentum has grown in the process of recognising that the inclusion and participation of people with disabilities is essential to human dignity and to the enjoyment and exercise of human rights (UNESCO, 1994). Several major events and declarations have highlighted the notion that special needs should be viewed as a social construct that reproduces the organisational inequalities that exist in society (Mitchell, 2005). This socio-ecological perspective acknowledges the "relationship between individuals and interactions between groups of people ... (such as families, classroom and schools), and has a significant impact on diagnostic findings as well as the support process" (Nel \& Grosser, 2016, p. 80). More recently, the emphasis has shifted to inclusive education that endorses education for all (EFA) being viewed as a fundamental human right in pursuit of social justice (UN, 2015). Although operational guidelines for the implementation of inclusion and transformation of Higher Education (HE) are available in South Africa (DoE, 1997), it appears that educational institutions and academics still struggle to implement essential policy in pursuit of educational transformation. This phenomenon is not limited to South Africa; this finding is corroborated by international research (Ebo, 2016). 
The imperative to offer equal opportunities and access for all and the efforts to do so are of leading concern in education today. This is evident in the international focus on the Sustainable Development Goals (SDGs) (UN, 2020) and Education for All (EFA) (UNESCO, 2005). The central theme of numerous policy-shaping declarations is that inclusion and participation is crucial to human dignity and to the exercising of human rights (Dreyer, 2017). While this movement has evolved to include all forms of discrimination and marginalisation (DoE, 2001), the inclusion debate started with a focus on disability that culminated in the adoption of the United Nations Convention on the Rights of Persons with Disability (UNCRPD) that states that "persons with disabilities should be guaranteed the right to inclusive education at all levels, regardless of age, without discrimination and on the basis of equal opportunity" (UN, 2008, p. 16).

The university in this study, along with other South African universities, prides itself on being an inclusive institution. According to the university's Disability Access Policy, "people with disabilities form part of the inclusion and diversity which SU embraces" (Stellenbosch University (SU), 2018, p. 5). However, as centres of learning and research, HEIs require more than policy and physical adaptations to buildings to effect transformation.

It is clear that the implementation of institutional policies on inclusion depends on a twopronged approach. First, it is the responsibility of the Disability Unit to support, enable, and coordinate the "functioning of students with disabilities on campus" (Stellenbosch University, 2018, p. 13). Second, it is imperative that academics be cognisant and reflective as Schön (983) has reminded us, of the presentation of modules as well as assessment procedures (Stellenbosch University, 2018) in pursuit of equal access and participation. At the same time, HEIs must take into account students' experiences of inclusion/exclusion to inform policy. In this small-scale research project, I investigated, from a human rights and social justice perspective, how education students with SLDs experience university.

\section{Disability as barrier to learning and participation}

The Education White Paper 6 (DoE, 2001) focuses mainly on the basic education system but for the purpose of this paper I use it to inform views on disabilities at HEIs. It must be noted that the transformation of the education system in South Africa acknowledges the "intricate interplay between intrinsic [medical] and extrinsic factors in the manifestation of learning disabilities" (Nel \& Grosser, 2016, p. 81). According to Education White Paper 6 (DoE, 2001, p. 12), the all-embracing term "barriers to learning and development" refers to a diverse range of factors and this may lead to the inability of the education system to address diverse needs that, in turn, may impact negatively on learning and prevent access to the provision of educational support. According to Dreyer (2015), these barriers to learning and development can be clustered into four broad categories: 1) systemic; 2) societal; 3) pedagogic and curriculum; and 4) intrinsic. Intrinsic barriers are further classified as neurological, physical, sensory, and cognitive. Since specific learning disabilities are neurological by nature this term is the umbrella one for various neurological conditions that can impact on learning and development. These include conditions such as epilepsy, cerebral 
palsy, learning disabilities, communication disorders, perceptual disorders, motor disorders, socio-emotional problems, memory problems, and attention problems. It is important to note that the terms specific learning disability or learning disability are primarily used in educational and legal systems to ensure that appropriate support is provided in school contexts. The medical term used for diagnosis and treatment is "learning disorder" (American Psychiatric Association, n.d., para. 5). With the growing awareness of inclusive education and the move away from a medical model in education, the terms learning difference and learning barriers are increasingly used in an attempt to move away from labelling learners as disordered or disabled. Therefore, from a social model and social justice perspective, it must be acknowledged that students who experience a neurological barrier might also experience pedagogic, systemic, and societal barriers (Dreyer, 2015). However, for the purpose of this paper I use the term Specific Learning Disabilities that is acceptable in South Africa in accordance with the American Psychological Association (APA).

Currently, the debates on inclusive education as well as identification and support for learners with barriers to learning are dominated by the schooling sector. While the policy for Screening, Identification, Assessment and Support (SIAS) (DoBE, 2014) provides a tool to address the needs of school children in basic education, at HEIs it is expected of students to self-declare what is called their disability in order to access support (Kendall, 2016).

\section{SLD: The invisible disability}

According to the Diagnostic and statistical manual of mental disorders (DSM-5) (American Psychiatric Association (APA), 2013), an SLD is a neurodevelopmental condition that is "diagnosed when there are specific deficits in an individual's ability to perceive or process information efficiently and accurately" (p. 32). This means that an SLD will affect the basic cognitive processes that are essential for comprehension and/or the use of spoken or printed language. Evidence of this condition may manifest as an inadequate ability to "listen, think, speak, read, write, and spell or to do mathematical calculations" (p. 32). The Learning Disabilities Association of America (LDA) (2018) states that people with learning disabilities are commonly of average or above average intelligence.

This is corroborated by research; Gow et al., (2020) concluded that it seems as if there is a gap between the individual's potential and her or his actual achievement. An SLD does not present with any physical or visible indications such as a physical or sensory disability so SLDs are often referred to as "hidden" disabilities (Couzensa et al., 2015, p. 24). Thus, in order to diagnose a specific learning disability, the DSM-V (APA, 2013) requires clinical assessment. However, in the move away from traditional standardised testing that is representative of the medical perspective on disability, the SIAS policy (DoE, 2014), proposes an array of strategies to perform diagnostic and curriculum-based assessment with the aim of providing appropriate support.

From a socio-ecological perspective, it is recognised that the experiences of students with SLDs is compounded in the presence of negative societal, systemic, and pedagogical barriers. 
Since HEIs are in a process of transforming to provide equal access to all students, it is important to be aware of these barriers among which are policy and curriculum issues, lack of basic and appropriate learning support materials, lack of assistive devices, inaccessible environment, inadequate facilities, management and classroom organisation, and inappropriate and inadequate support services (DoE, 2001). Teachers are obligated to work within the confines of the national and institutional policies and support structures of educational institutions.

However, teachers have more control over the following possible pedagogical barriers: inappropriate teaching methodologies and strategies; inappropriate and unfair assessment procedures; and insufficient support available to students. For the purposes of this paper, it is, therefore, significant to recognise that the experiences of students with SLDs are complex.

\section{An HEI as a space for all}

Research has shown that internationally there is an increase in the number of students with disabilities who enrol in universities (Ebo, 2016). With this move towards inclusive education, universities are consequently challenged to create spaces of excellence for all (including students with disabilities) in a democratic and socially just system. Internationally, HEIs have taken up this challenge but have focussed primarily on making buildings accessible for wheelchairs and ease of access for other more visible disabilities. More recently, universities have also realised the need to develop policies to support students with special learning needs such as SLDs that are not physically visible. While systemic barriers to equal access and participation at universities are addressed through policy development and physical structures, practical implementation in learning spaces tends to be neglected (Kendall, 2016; Ryan, 2007).

If the construct of pedagogy is seen to be the complex interplay between teaching and learning in inclusive education (Flores, 2019; Loughran, 2013), it requires universities to reflect on how barriers to learning and participation of students with SLDs in higher education impact on their experiences. According to Couzensa et al. (2015), certain adjustments need to be made to the traditional ways in which these students are expected to navigate the teaching and learning environment. The adjustments they suggest include "1) extended time to complete the programme, 2) course substitution, 3) modification or waiver of a foreign language requirement, 4) part-time study, and 5) extended time for tests" (p. 25). However, such adjustments tend to be generic and put most of the onus on the individuals who must declare their disability to the university (Kendall, 2016). Since SLDs are invisible such declarations are required to be supported by psychological assessments (Couzensa et al., 2015).

\section{Experiences of students with SLDs in higher education}

Research indicates that although there are policies to encourage and enable inclusion in HEIs and funding is provided, this does not necessarily achieve the desired results for students 
(Ryan, 2007). It is thus imperative that the voices of this population group are heard. Understanding the experiences of students with SLDs can contribute to addressing the barriers they experience (Gibson, 2012). While research in inclusive education indicates positive learning experience and academic outcomes generally, it is also reported that "beyond the surface of institutional policy, the reality of university life for students with disabilities is one of continued exclusion and barriers to learning" (Gibson, 2012, p. 354). According to Vickerman and Blundell (2010, p. 22) this gap is a result of HEIs that do not sufficiently adopt "positive strategies to consult disabled students when implementing policies and practices to break down barriers to study."

In pursuit of inclusive education, it is important to note the impact of learning experiences for students with SLDs. In a study conducted by Ryan (2007) all the students who were interviewed reported various difficulties with their learning. These included difficulty with reading written material, essay writing, understanding lectures as well as participating in tutorial or seminar discussions. Similar findings emanated from research conducted by Kendall (2016) in the north of England and Strnadová et al. (2015) at Czech universities. This negative impact on learning is indicative of the barriers caused by SLD as a neurological condition. Because SLDs are not visible in the same way that sensory and physical disabilities are (Couzensa et al., 2015), they may go unidentified if not disclosed and, consequently, will not be addressed. The aim of this study, therefore, was to listen to the voices of those who are labelled with a learning disability and who "have been largely discounted and marginalized, unheard by the rest of us" (Smith, 1996, p. 118).

In this paper, therefore, I make a case for illuminating the experiences of students with SLDs at university. With this emphasis on the students' voices, policy that will result in the development and the provision of student support services at HEIs can be informed.

\section{Materials and method}

I designed this case study research and conducted it within a basic qualitative research methodology, embedded in an interpretive paradigm following Patton (2015). An interpretive approach allowed me to study the participants' subjective experiences (their ontology) of the external world. The rationale for choosing an interpretive paradigm for this research was that it focusses on describing how individuals make sense of their lives in natural settings as Merriam and Tisdell (2016) have pointed out. I followed Patton's (2015) suggestion that the researcher may adopt an intersubjective epistemological stance toward reality and use methodologies that rely on a subjective relationship between her or him and the subject. This led to my data collection and analysis methods being qualitative in nature.

This research was further guided by Schunk's (2012) work on Vygotsky's social cultural theory (SCT) that embraces the notion that social, cultural-historical, and individual factors are key factors in human development and learning. Unlike theories such as behaviourist (stimulus-response that leads to changed behaviour) and cognitive (information processing in order to learn) that are favoured in higher education, SCT is aligned with the constructivist 
paradigm. It recognises that individual biological factors play an important role in the learning process (Schunk, 2012, Vygotsky, 1978).

The significance of the SCT for this paper is that one of its key proponents is that learning and development take place on two levels (Schunk, 2012). Learning happens first at a social level between or among other people (for example in a classroom situation or other similar contexts) and knowledge is co-constructed during shared activities. These shared activities could be a class discussion, tutorial, or any learning activity that involves more than one person. Learning then happens at a second level as knowledge is internalised and consolidated at an individual level. New knowledge and skills are internalised through conscious efforts by the individual to remember and understand these. The newly constructed and internalised knowledge then becomes part of the individual's cognitive repertoire (Vygotsky, 1978). It is clear, therefore, that socio-cultural theory and a social constructivist paradigm pose significant implications for the pedagogical approaches that lecturers use during lectures and other academic activities.

However, SCT also postulates that the complex interaction between and among socio-cultural factors, such as disability, identity, and history, is significant in understanding human development. Since SCT has been associated with contemporary work on inclusive education theory, practice, and policy, Gibson (2012) argued that it offers a critical lens that can provide insight into applications of inclusion. This is supported by Valenzuela (2007, p. 286) who argued that SCT can provide a "rich and strong theoretical backbone when addressing complex aspects of educational exclusion."

The research question that guided this research was: What are the university experiences of undergraduate students with specific learning disabilities (SLDs)?

\section{Selection of participants}

I purposefully selected the participants from the B.Ed. program in the Faculty of Education at a South African university. The criteria for participation were that they had to be full-time registered students currently studying education in the Faculty of Education and must have been

- diagnosed with a specific learning disability while at school and

- have received educational and assessment support up to and including grade 12.

Only first and second year students were invited to take part voluntarily in this research project. The rational for this is that the specific university has implemented a new B.Ed. program as required by the Minimum Requirements for Teacher Education Programs (MRTEQ) (DoHE, 2019). The new programme was in its second year of implementation during the undertaking of this research, so it was limited to students in the new B.Ed. programme. An invitation to participate was sent to students via the university's Moodle platform, SUNLearn. With the initial invitation, students had to indicate their willingness to take part in the project. Nine second-year students and five first-year students responded 
positively to the invitation. I acknowledge that this is a very small sample from only two year-groups from only one faculty. Therefore, I do not intend generalising the findings from this small-scale research project.

Since I was also the lecturer for some of the participants, it was important that they understood the rationale for the research. Therefore, I followed up the positive responses from students willing to participate with an explanation of the purpose of the research and what would be required from them. Informed consent was explained to them to which they agreed online. This was done to circumvent the power relationship that exists between lecturer and student. Ethical clearance from the university's research committee and institutional permission to do the research was obtained before I began this small scale interpretive qualitative research project.

\section{Data collection}

I collected data through an online qualitative background survey. At the end of the survey participants were asked if they would be willing to be interviewed. Those who voluntarily engaged in a semi-structured interview provided me with deeper insight into the experiences of undergraduate students with SLDs studying at the university. Following Patton (2015) I developed an interview guide that helped me to formulate a list of questions to explore during the interviews. The following are examples of questions that guided these semi-structured interviews: How did you become aware of support services for students with disabilities at the university? Did you inform your lecturers about your support needs? If NO - Why not? These methods (background survey and semi-structured interviews) are some of those preferred by researchers like Merriam and Tisdell (2016) who work in an interpretivist paradigm

\section{Data analysis}

In line with qualitative research, I used thematic qualitative content analysis to analyse collected data systematically. I transcribed the data collected from the survey and coded it using a descriptive approach in line with Patton (2015). Through data analysis I identified regularities and patterns and coded them to represent the topics covered. Following Merriam and Tisdell (2016), I used coding to identify patterns and extrapolate themes that emerged from the collected data. I used an interview guide, with a list of prompts and themes that emerged from the survey to guide the semi-structured interviews. I audio-recorded the interviews with permission from the participants.

\section{Results and discussion}

As mentioned above, nine second-year students and five first-year students were willing to participate in the online survey. They were not required to identify their race or gender. The only requirement was that they, through accepting the invitation, consciously self-declared that they had been identified as having an SLD. 
The following themes emerged from the collected data:

1. Concessions received at school

2. Knowledge of support structures at university

3. Experiences of inclusion

4. Request for support

5. Factors contributing to academic success

I use these themes to present and discuss the findings in the following section.

\section{Concessions received at school}

From the questionnaire it was clear that most of the participants' SLDs were identified by teachers during primary school. While some were identified quite early in primary school, others, like this second-year student were identified in Grade 6: Respondent 1 (second year) wrote,

In junior school in grade 6, i went for learner testing where i got 5 mins extra per exam. In grade 9,10,11,12 i had a reader at school as listening to content is easier for me and i struggle with reading.

Data, in Table 1 below, reveals that support provided at school level was focussed on giving this during assessment opportunities in the form of concessions. From the given list of the most common assessment concessions participants received at school, most participants (6) indicated that they got extra writing time for examinations. Only 1 specified that a scribe was allocated. As noted above, Respondent 1 indicated that a reader (not in the list provided) was provided in high school. Those participants who indicated NONE on the list, explained during the interviews that they had received various forms of informal support from their teachers in primary school. With the mainstream classroom as the first level of support, this is mandatory as set out by the requirements of the Department of Education as stated in the Education White Paper 6 (DoE, 2001). However, while the White Paper specifies that "teaching methodologies, curricula and the environment [need] to meet the needs of all learners" (p. 16), it seems as if most of the support provided by teachers is aimed generally at providing assessment concessions. This finding confirms Ryan's (2007, p. 437) assertion that support is generally more focussed on the provision of add-on "remediation programs, such as extra tutorial assistance, assignment extensions, or transition and outreach programs."

\section{Table 1}

Participants receiving support at school

\begin{tabular}{|c|c|}
\hline $\begin{array}{c}\text { Common concessions } \\
\text { provided for at school }\end{array}$ & $\begin{array}{c}\text { Number of } \\
\text { respondents }\end{array}$ \\
\hline Extra writing time & 6 \\
\hline Spelling concessions & 0 \\
\hline
\end{tabular}




\begin{tabular}{|l|l|}
\hline Enlarged print & 0 \\
\hline Scribe & 1 \\
\hline Separate venue & 0 \\
\hline Recordings & 0 \\
\hline Computer & 0 \\
\hline NONE & 6 \\
\hline
\end{tabular}

\section{Knowledge of support structures at university}

As new students who were diagnosed with SLD, they need to be aware of the support structures that the university has to offer. At HEIs, support structures generally refer to assessment concessions (including extra time, spelling concessions, and Braille facilities and sign language interpretation during lectures and assessment) and physical adaptations (such as wheelchair friendly buildings). For students with SLDs, assessment concessions are important to ensure continuation and/or improvement on the kinds of support provided at school level. This is consistent with Prosser and Trigwell's (1999) assertion that there is a link between prior experiences and current teaching and learning situations. However, from the responses of participants to the online questionnaire it became apparent that new undergraduate students generally did not know about support that is provided at university level before they started the academic program. Initially, some of the students did not even know that they could apply for academic support (such as extra writing time, spelling concessions, enlarged print, etc.) because of the diagnosis they have been given while some found out about possible support only in the first week on campus during the orientation sessions. In other cases, parents played an instrumental role when they enquired about and secured support for their children as seen in this response: "My mom emailed the university to find out who she should contact." Then there was another group who realised that there was academic support provided by the university only when they "met with tutors", while other participant mentioned that they saw "in classes when people [got] extra time" for examinations. One other participant reported, "I asked someone who I knew had gotten support [extra writing time] before."

From the above findings it is clear that new undergraduate students generally are not aware initially of any support structures available at university, of which assessment concessions are the most common. It is quite concerning that some realised that support is possible only when they saw classmates receive support in the form of extra time during assessments. As the traditional student profile of universities changes (Biggs, 2012) it becomes imperative that HEIs acknowledge and ensure that all students have equal access that does not refer only to social access but also to knowledge of various support structures that will enable equal and full participation in the academic program. It is, therefore, important that information regarding available support be made more readily available on many platforms. Prospective students should be made aware of any possible academic and other support structures 
available without fearing that they need first to self-declare their need for support or only become aware of possible support after having enrolled and started the academic program.

In my pursuit of this theme, it became apparent that not all students felt comfortable about self-declaring their SLD and are thus reluctant to request any form of academic support. From the semi-structured interviews, it was clear that most students did not feel comfortable requesting support at university level or from individual lecturers for various reasons. Some students have learned to cope with their condition. In general, they expressed the opinion that, although they received support in school, they do not need it any longer because they can control the condition with medication. They further expressed the need to function independently without additional support as indicated in the following statements.

I did not ask for support, because I want to grow as a student, and I feel that I don't need it anymore. Although I'm using Concerta [an extended-release form of methylphenidate, a drug used to treat attention-deficit/hyperactivity disorder and narcolepsy] still.

The extra time helped me more in high school than in university, especially in math, sciences and EGD.

Additionally, there were those who were reluctant to ask for help since they did not want to be seen to contribute to extra work for tutors or lecturers as voiced by this second-year student, "I felt like i needed it but in the classes I really needed it. It was not very helpful as the tutors felt they didn't have to do extra work." Some students were reluctant to request support since they seemed to have had negative experiences in the past or were seen to be getting special treatment, as these students explained.

I am on medication and I'm trying to work independently and also not receive special treatment.

I felt like I would do it myself because of the bad experiences [I] didn't feel comfortable.

This response again correlates with Prosser and Trigwell's (1999) assertion that aspects of prior experiences may be evoked and will have an impact on what and how students learn. These students clearly do not want to be labelled or stigmatised and would rather refrain from letting lecturers know that they have specific learning needs that require additional support. From a pedagogical standpoint, lecturers need to be aware of the limitations that labelling place on learning. Hart et al. (2004) referred to learning without limits as

learning that is free from the needless constraints imposed by ability-focused practices, free from the indignity of being labelled . . . free from the wounding consciousness of being treated as someone who can aspire at best to only limited achievements. 
It requires conscious efforts on the part of teaching staff to create a welcoming and inclusive space for learning. Furthermore, in the light of possible previous experiences, students commenting that they do not want to be treated like someone who gets "special treatment" may suggest their need to justify their presence at university. This can be seen as a form of defence since some lecturers who believe it to be an elitist institution, reserved for a few (Biggs, 2012) might be of the opinion that these students should not be at university in the first place. These findings point to the obligation for university lecturers to reflect on their own pedagogical practices. Lecturers should plan to include all students and their being reflective practitioners should be an integral part of their teaching and learning process (Schön, 1983). This is particularly relevant in a faculty of education that prepares students for the teaching profession (Department of Higher Education, 2019).

There was one student, however, who had excelled at school, could attend university despite the SLD diagnosis, and had a very positive outlook. This participant welcomed the support provided and said, "I am not embarrassed ... that I had to request academic support. I am more proud that I am able to be at university despite having a learning disability." Another, who took on an alternative stance towards informing lecturers about support needs, said, "I only needed the support during exams and test, I didn't think it was the lecturers' business as it didn't affect me in class."

\section{Experiences of inclusion}

To the interview question about whether they feel included in class during lectures, most of the first-year students reacted positively since they experienced a general feeling of being included in academic activities. There was only one exception; a participant indicated not feeling included and explained, "No, because I did not made them aware of my issue." It seems that this participant was experiencing difficulties in class but was reluctant to seek help. This finding correlates with that of Kendall (2016) that students are reluctant to declare their disability or seek help because of the perceived stigma associated with disability. This reaction could be a function of various reasons as mentioned earlier, such as possible prior negative experiences and fear of stigmatisation, or that they were not aware of possible support from the university. In contrast, most second-year students were ambivalent since they experienced varied forms of inclusion (or exclusion) from class to class. Some experiences were related to lecturers who do not give timely feedback or respond to students' enquiries as seen in the following response.

No. I usually feel like I am bound to do things on my own and lecturers take their time to respond to my emails. It is annoying and caused me to fail some modules.

One student who felt excluded from the class, specifically mentioned the difficulty experienced in trying to keep up.

No. It is difficult for me to keep up in class and make notes. it would help so much if the notes on sunlearn [the online portal] were more detailed. 
As articulated earlier, the socio-constructivist view of Vygotsky (see Schunk, 2012) is that learning first occurs at a social level. At an educational institution this refers to educational interactions between people in and beyond the classroom. In pursuit of equity and equal access to quality education and support, it is imperative that lecturers are conscious of this requirement of learning. This is particularly relevant in diverse classroom contexts that increasingly include students with SLDs. Given their specific needs, these students may be in greater need of those lecturers who engage in student-focused teaching. With a studentfocused approach, lecturers can address the needs of all students and create a welcoming class atmosphere in which students can feel free to ask for support. According to Biggs (2012), strategies that are student-focused can bring about the desired conceptual change in how students understand and subsequently have a positive impact on how they approach their studies as part of the process of internalisation as the second level of learning in order to succeed academically.

However, lecturers also need to be aware that some students need to be independent and do not want to be perceived as a burden. The need to feel included is expressed in the need to be inconspicuous in class. One participant said that "it is better not be made to feel like an exception in the class." Students want to feel included naturally: "Yes [I feel included since] they [lecturers] don't do anything different which keeps me comfortable and included normally." This reaction, too, may be to the result of prior experiences of stigmatisation. This inference is made because the student used the word "normally" as if it would not be normal to be included by lecturers who consciously think and apply their pedagogy to include everybody in class. This finding too correlates with a similar finding by Kendall (2016) who attributes this reaction of students with disabilities partially to the negative attitudes of society towards people with disabilities. This is quite concerning since, in being pre-service teachers, it is important that these participants, too, should learn to differentiate and support a diversity of learners within an inclusive education system.

\section{Request for support}

Most participants, 4 of the 1st year cohort and 6 of the 2nd year class, indicated that they would rather ask a classmate or friend for help when necessary. In the 1st year group only 1 indicated that the lecturer would be asked for help while in the 2 nd year group none indicated that they would ask a lecturer for help. However, 3 indicated that they would rather ask a family member for help. Requesting support implies disclosure and risks possible stigmatisation (Kendall, 2016). These findings further correlate with results of a study by Ebo (2016) who suggested that students "feared that the professor would think they were incapable of handling the course work" (p. 83) and therefore did not seek their help.

\section{Factors contributing to academic success}

When asked what factors they felt contributed to their academic success, most (4 out of the 5) participants in the 1st year group mentioned support from their friends while only 1 regarded support from lecturers as contributing to their academic success thus far. It was interesting that in the 2 nd year group, 7 out of 9 indicated that family and friends were the main 
contributors to their academic success. Only 1 attributed success to concessions received and 1 to student support services at university. It is clear that support from lecturers and university support structures played a secondary role in these students' perceptions of their success. The lack of support experienced by most students in this small-scale study clearly indicates a need for lecturers to reflect on their pedagogical practices if authentic inclusion is to be realised. However, this is not limited to this specific university since similar findings were reported by Couzensa et al. (2015) in which student support services were not indicated as a resource that contributed to students' success. Furthermore, the findings correlate with other findings from the literature (Kendall, 2016; Ryan, 2007) on student experiences of support from lecturers. It is concerning that none of the participants in the 2 nd year group attributed their current experiences of success to their lecturers. According to this study students valued the support of family and friends more than that of lecturers.

The transformation of the South African education system requires a strong emphasis on inclusive education in pursuit of social justice as enshrined in the South African constitution (Republic of South Africa (RSA), 1996). It is therefore clear that changes in higher education are inevitable. It is, however, imperative that these changes transcend beyond policy development towards social inclusion and implementation. However, according to Buller (2015), while much attention is being paid to change in higher education, there seems to be a resistance to change in general.

I acknowledge that the university has developed policies to include students with disabilities as part of the national transformation aimed at creating an inclusive society, free from all forms of discrimination (Stellenbosch University, 2018). The issue here is that SLDs are often referred to as invisible disabilities since there is no physical indication of them as Couzensa et al. (2015) have reminded us. However, since basic education systems are increasingly supporting students who have been identified with an SLD, they, too, are increasingly entering higher education (Couzensa et al., 2015; Kendall, 2016; Ryan, 2007). Tertiary educational institutions are thus challenged to admit students with SLDs and, at the same time, provide them with opportunities for equal participation. SCT proposes that the first level of learning is determined by the quality of social interactions. With this in mind, university lecturers should be aware of the impact of their pedagogy and take into account the individual physical and biological factors that impede the learning of students with SLDs.

\section{Conclusion}

The responses of the participants in this small-scale study epitomise the effect of SLD as an invisible disability on their lived experiences of university. From a human rights and social justice perspective, there are several factors that impede equal education and "promot[e] universal access for people with disabilities" such as SLDs at university. It can be concluded that although the university has policies to promote inclusion, some students with SLDs still do not experience "fundamental rights and freedoms ... on campus, as required by the Constitution and related legislation" (Stellenbosch University, p. 6) being met. 
In pursuit of being an "inclusive, innovative and future-focused" (Stellenbosch University, p. 5) university we need to create learning spaces that embrace diversity beyond physical and sensory disability on two levels. The first is the institutional level where policies are developed and the information on available support to students with SLDs at the institution is disseminated. The second is the classroom level where lecturers need to ensure that policy is implemented through their pedagogy. Given that pedagogy is considered to refer to the complex inter-relationship between teaching and learning (Loughran, 2013), teachers in HEI need to take heed of factors that affect the learning of students with SLDs. While this research focused on overall university experiences, I suggest that research be conducted into the actual pedagogical practices (methodologies, strategies, and techniques) of lecturers in relation to students' experiences of being included. This will enhance the understanding of student experiences at classroom level.

The findings from this study indicate the need for lecturers to be cognisant and reflective practitioners in pursuit of authentic inclusion. No student should say, "I don't want to be seen to be getting special treatment" but should, rather, be able to claim equal access and participation as a basic human right.

\section{Funding}

This research did not receive any specific grant from funding agencies in the public, commercial, or not-for-profit sectors.

\section{References}

American Psychiatric Association. (2013). Diagnostic and statistical manual of mental disorders: DSM-5 (5th ed.). American Psychiatric Publishing.

American Psychiatric Association. (n.d.). Specific learning disorder. https://www.psychiatry.org/patients-families/specific-learning-disorder/what-isspecific-learning-disorder.

Biggs, J. (2012). What the student does: Teaching for enhanced learning. Higher Education Research \& Development, 31(1), 39-55.

Buller, J. L. (2015). Change leadership in Higher Education: A practical guide to academic transformation. Jossey-Bass.

Couzensa, D., Poedb, S., Kataokac, M., Brandond, A., Hartleye, J., \& Keenf, D. (2015). Support for students with hidden disabilities in universities: A case study. International Journal of Disability, Development and Education, 62(1), 24-41. https://doi.org/10.1080/1034912X.2014.984592

Department of Education. (1997). Education White Paper 3: A programme for the transformation of higher education. Department of Education. 
Department of Education. (2001). Education White Paper 6: Special needs education: Building an inclusive education and training system. Department of Education.

Department of Basic Education. (2014). National strategy on screening, identification, assessment and support. Government Printer.

Department of Higher Education. (2018). Strategic policy framework on disability for the post-school education and training system. Department of Higher Education.

Department of Higher Education. (2019). Policy on the minimum requirements for teacher education qualifications, as revised 2018. Department of Higher Education.

Dreyer, L. M. (2015). Experiences of parents with children diagnosed with reading difficulties. Southern African Review of Education, 21(1), 94-111.

Dreyer, L. M. (2017). Constraints to quality education and support for all: A Western Cape case. South African Journal of Education, 37(1). https://doi.org/10.15700/saje.v37n1a1226

Ebo, B. A. (2016). Understanding the experiences of college students with learning disabilities (Unpublished doctoral dissertation). North Eastern University, Boston, MA, United States.

Flores, M. A. (2019) The complex interplay of variables in studying teacher education. European Journal of Teacher Education, 42(2), 131-134, https://doi.org/10.1080/02619768.2019.1575092

Gibson, S., (2012). Narrative accounts of university education: Sociocultural perspectives of students with disabilities. Disability \& Society, 27(3), 353-369. https://doi.org/10. 1080/09687599.2012.654987

Gow, M., Mostert, Y., \& Dreyer, L. M. (2020). The promise of equal education not kept: Specific learning disabilities - the invisible disability. African Journal of Disability, 9, a647. https://doi.org/10.4102/ajod.v9i0.647

Hart, S., Dixon, A., Drummond, M. J., \& McIntyre, D. (2004). Learning without limits. Open University Press.

Kendall, L. (2016). Higher education and disability: Exploring student experiences.

Curriculum and Teaching Studies (Cogent Education), 3, 1-12.

Learning Disabilities Association of America (LDA). (2018). Types of learning disabilities. LDA-WhatAreLDs-CP-10102018.docx (ldaamerica.org)

Loughran, J. (2013). Pedagogy: Making sense of the complex relationship between teaching and learning. Ontario Institute for Studies in Education of the University of Toronto Curriculum Inquiry, 43 (1), 118-141. 
Merriam, S. B., \& Tisdell, E. J. (2016). Qualitative research. A guide to design and implementation. Jossey-Bass.

Mitchell, D. (2005). Introduction: Sixteen propositions on the contexts of inclusive education. In D. Mitchell (Ed.), Contextualizing inclusive education (pp. 1-21). Routledge.

Nel, M., \& Grosser, M. M. (2016). An appreciation of learning disabilities in the South African context. Learning Disabilities: A Contemporary Journal, 14(1), 79-92.

Patton, M. Q. (2015). Qualitative research \& evaluation methods: Integrating theory and practice. Qualitative research and evaluation methods (4th ed). Sage.

Prosser, M., \& Trigwell, K. (1999). Understanding teaching and learning: The experience in higher education. The Society for Research into Higher Education and Open University Press.

Ryan, J. (2007). Learning disabilities in Australian universities: Hidden, ignored, and unwelcome. Journal of Learning Disabilities, 40(5), 436-442.

Republic of South Africa. (1996). Constitution of the Republic of South Africa. Government Printer.

Schön, D. A. (1983). The reflective practitioner: How professionals think in action. Basic Books

Schunk, D. H. (2012). Learning theories: An international perspective. Pearson.

Smith, P. (1996). Drawing new maps: A radical cartography of developmental disabilities. Review of Educational Research, 69, 117-144.

Stellenbosch University. (2018). Disability Access Policy. www.sun.ac.za/policies

Strnadová, I., Hájková, V., \& Květoňová, L. (2015) Voices of university students with disabilities: Inclusive education on the tertiary level — a reality or a distant dream? International Journal of Inclusive Education, 19(10), 1080-1095. https://doi.org/10.1080/13603116.2015.1037868

UNESCO. (1994). Salamanca statement and framework for action on special needs education. https://www.right-to-education.org/sites/right-toeducation.org/files/resource-attachments/Salamanca_Statement_1994.pdf

UNESCO. (2005). Guideline for inclusion: Ensuring access to education for all. http://www.ibe.unesco.org/sites/default/files/Guide lines_for_Inclusion_UNESCO_2006.pdf.

United Nations. (1948). Universal declaration of human rights. https://www.un.org/en/universal-declaration-human-rights/index.html 
United Nations. (2008). Convention on the rights of persons with disabilities.

https://www.un.org/disabilities/documents/convention/convoptprot-e.pdf

United Nations. (2015). Transforming our world: The 2030 agenda for sustainable development.

https://sustainabledevelopment.un.org/content/documents/21252030\%20Agenda\%20f or\%20Sustainable\%20Development\%20web.pdf.

United Nations. (2020). Sustainable development goals report.

https://www.un.org/sustainabledevelopment/progress-report/

Valenzuela, J. S. (2007). Socio-cultural views of learning. In L. Florian (Ed.), The Sage handbook of special education (pp. 280-289). Sage.

Vickerman, P., \& Blundell, M. (2010). Hearing the voices of disabled students in higher education. Disability and Society, 25(1), 21-32.

Vygotsky, L. (1978). Mind in society: The development of higher psychological processes. Harvard University Press. 